\title{
How wired are we? New data on library technology
}

\author{
By Mary Jo Lynch
}

\section{Two-tbirds of academic institutions have Internet access}

\section{D}

o all academic libraries have electronic catalogs? Can they be accessed from off campus? How many four-year college libraries subscribe to electronic journals? How many libraries in two-year schools have access to the Internet?

Answers to those questions and many others were sought in a study done for the Corporation for Public Broadcasting (CPB) by SRI International (formerly Stanford Research Institute). CPB recently published a brief summary report of this study (available by contacting CPB Publications, 901 E Street, N.W., Washington, DC 20004; (202) 879-9764). Because that summary does not mention libraries, CPB gave ALA permission to present some of the key findings on that topic to the library community

\section{Study design}

In the spring of $1994, \mathrm{CPB}$ conducted a comprehensive, multifaceted national survey of 1,000 higher education institutions concerning the instructional uses of communications technology, including audio, video, multimedia, and computers. The study was done to help CPB plan for the future of public telecommunications. It included six institution-level questionnaires designed to assess the following topics: use of computer technologies in the libraries; availability and way in which computers are used for instructional purposes; use of audio, video, and multimedia technologies in the classroom; use of audio, video, multimedia, and computer technologies in teacher education; use of distance education technologies; and institutional policies and chief academic officers' perceptions of current and future use of instructional technologies. Questionnaires on those topics were sent to a random sample of institutions stratified by using the Carnegie Classification. In addition, questionnaires were sent to a subsample of faculty in 100 of those institutions and telephone interviews were conducted with a national sample of students. This article summarizes results of the questionnaire on libraries. In the text and in the bar charts I refer to the seven Carnegie Categories used in the CPB study.

\section{Electronic catalogs}

Most academic libraries have electronic catalogs today, and many that don't have them now will have them within a few years. Figure 1 shows the percent that have electronic catalogs and the percent that will soon add them by level of institution. Virtually all of the cata-

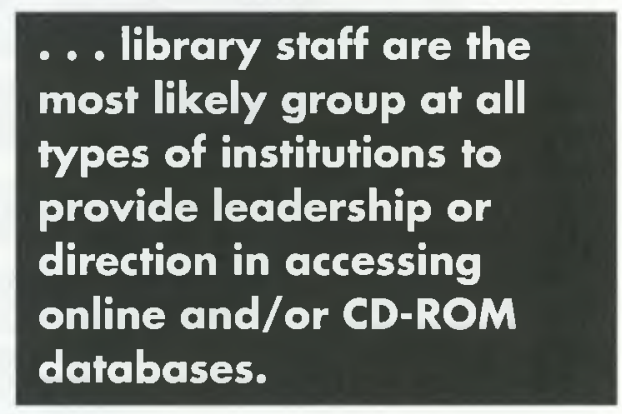

logs are accessible from terminals/PCs in the library. Well over $50 \%$ can also be accessed through dial-up access from outside the library, through a campus network, and through an outside nerwork, except for public two-year insti- 
Figure 1

Electronic Catalogs

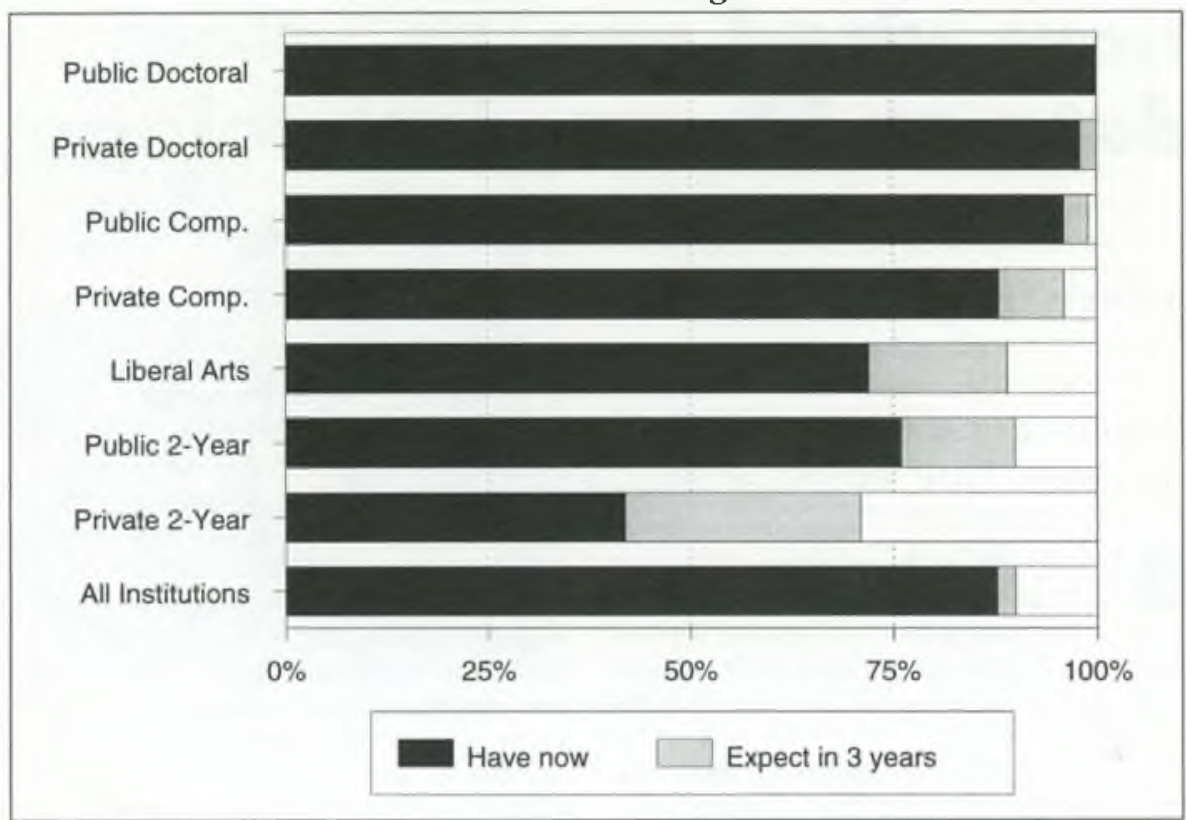

Figure 2

Subscriptions to Electronic Journals

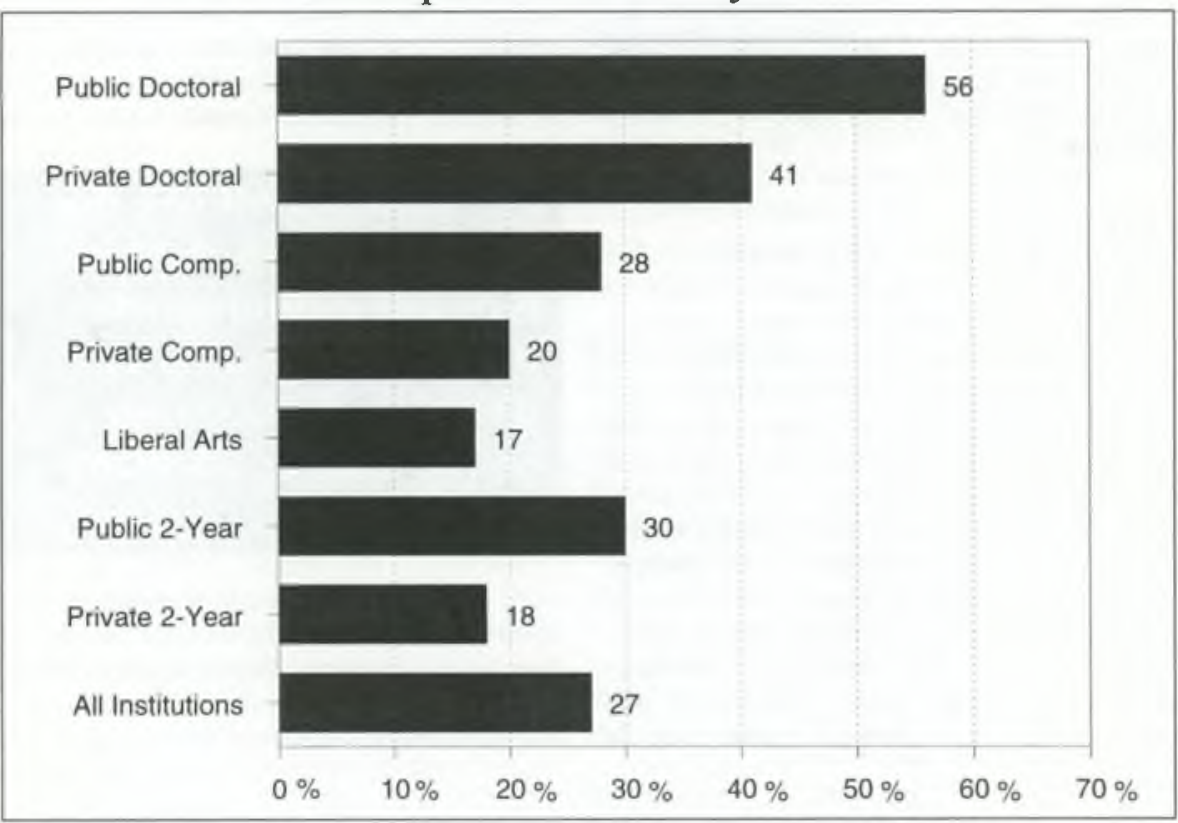


tutions where the percentages for those three types of access are $48 \%, 35 \%$, and $24 \%$ respectively. Figures are not available for private twoyear schools because there were too few respondents to provide reliable estimates.

\section{CD-ROMs and electronic journals}

The CPB found that multimedia CD-ROMs were available for use in $57 \%$ of academic libraries and text-only CD-ROMs were available in $85 \%$ of libraries. These CD-ROMs were rarely available for loan outside the library. Computer software was available for use in $54 \%$ of the libraries, with $20 \%$ allowing loan. Overall, more than a fourth of the libraries subscribe to electronic journals, but there is considerable variation by type of institution as shown in Figure 2.

\section{Bibliographic and full-text resources}

Access to external online bibliographic resources (e.g., DIALOG, ERIC) is almost universal in doctoral, comprehensive, and liberal arts institutions. In two-year schools, $63 \%$ of public institutions and $37 \%$ of private institutions of fer such access. In libraries that offer these services they are available at no cost to students at
$45 \%$ of institutions and to faculty at no cost at $50 \%$ of institutions.

The access figures are lower for CD-ROMbased external bibliographic resources. Among the doctoral and comprehensive institutions the range is from a low of $52 \%$ (private doctoral) to a high of $67 \%$ (public doctoral), with the comprehensive schools in between. CD-ROM bibliographic resources are held by $54 \%$ of liberal arts college libraries, $39 \%$ of public twoyear schools, and $36 \%$ of private two-year schools. There were no doctoral-level institutions that did not offer any access to external databases (online or CD-ROM), and less than $10 \%$ of comprehensive and liberal arts institutions lacked that access. Among two-year institutions, $27 \%$ of the public schools and $48 \%$ of the private schools did not provide access to either external online bibliographic resources or external CD-ROM-based bibliographic resources.

External online full-text databases are offered by over $70 \%$ of doctoral institutions, $43 \%$ of public comprehensive, and less than $40 \%$ of all other categories. At $61 \%$ of institutions that offer them, online full-text resources are available gratis to both students and faculty.

Figure 3

Access to Internet/Bitnet

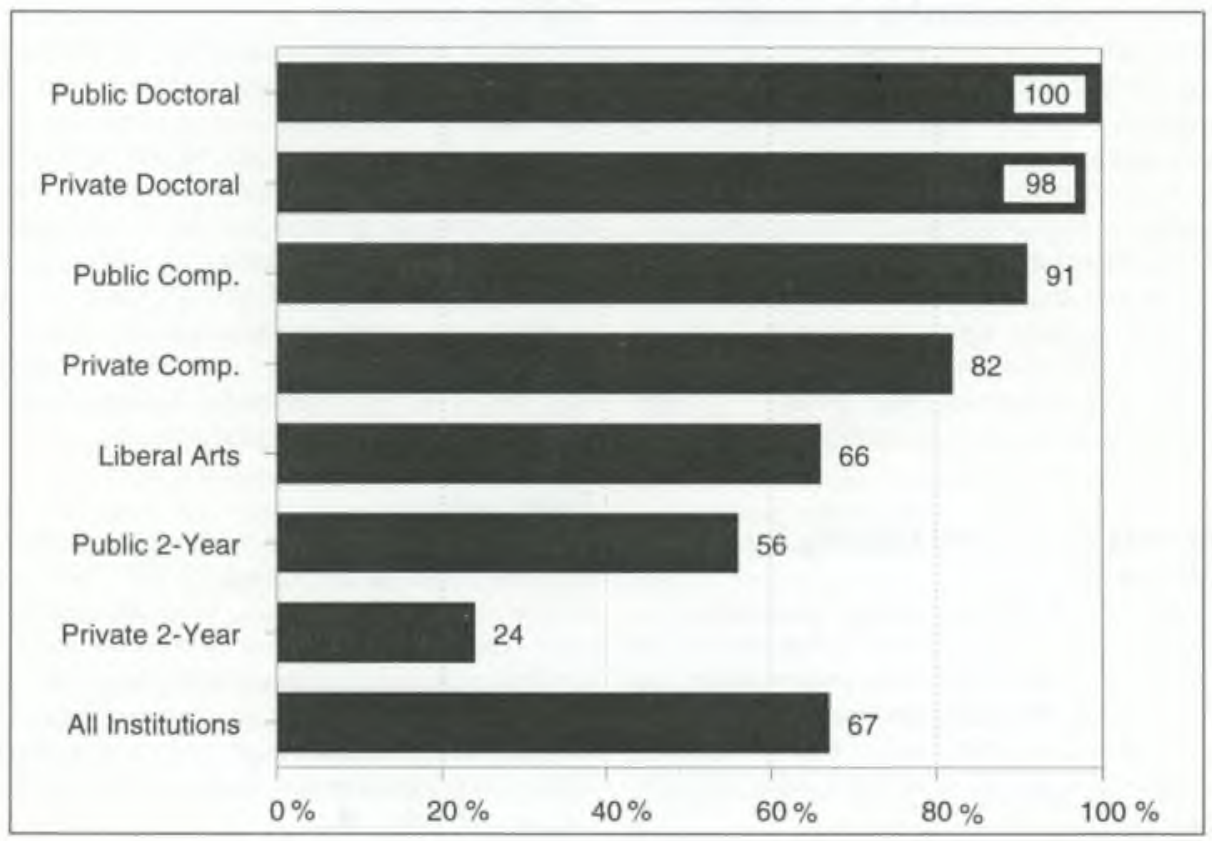


Figure 4

Changes Made in the Past Three Years

to Support Electronic Access to Materials

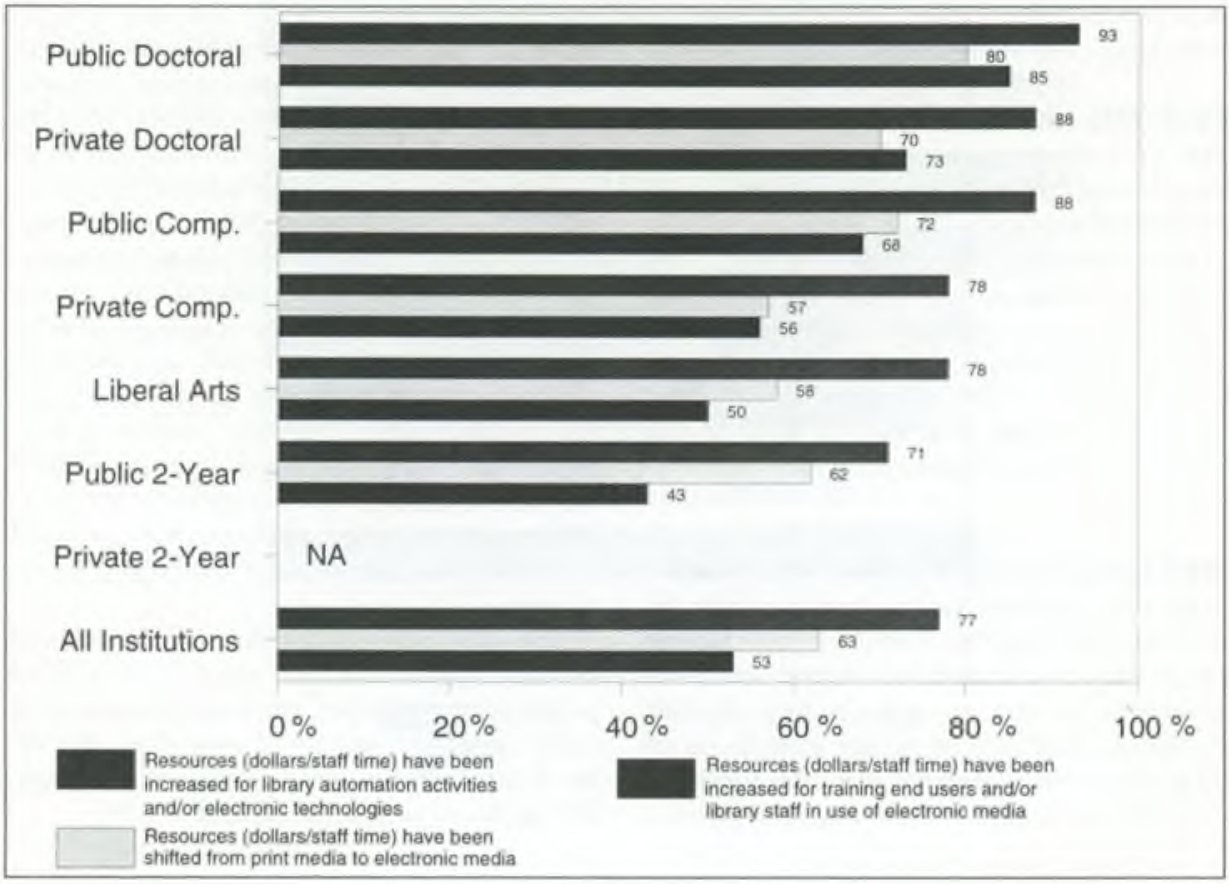

\section{Institutional leadership in academic libraries}

According to chief academic officers who responded, library staff are the most likely group at all types of institutions to provide leadership or direction in accessing online and/or CD-ROM databases. At almost three-fourths of institutions $(71 \%)$, library staff provide leadership or direction in this area. They are especially likely to do so at private comprehensive and private doctoral universities $(82 \%$ and $90 \%$ respectively). The next most likely group to provide leadership in this area is academic computing staff $(42 \%)$.

\section{Internet access and training by staff members}

Two-thirds of the responding institutions reported that their libraries are connected to the Internet. Figure 3 (previous page) shows the variation by type of institution. Among those that have access, $80 \%$ report that library staff provide training and/or answer questions about the Internet.

\section{Shifting resources}

Almost all institutions reported some changes in the three years preceding the survey to support increased reliance on electronic media. Figure 4 shows the percent of each type of institution reporting three kinds of change: resources have been increased for library automation activities and/or electronic technologies; resources have been shifted from print media to electronic media; resources have been increased for training end users and/or library staff in use of electronic media. Figures are not available for private two-year schools.

\section{Future plans}

ALA will be conducting a survey of these topics plus more in the spring of 1996 using a similar sample design (i.e., Carnegie Categories). This is a joint project of the ALA Office for Research and Statistics (ORS) and the Association of College and Research Libraries (ACRL), with financial support from Ameritech Library Services. A report will be published by ALA in fall 1996. 